\title{
ADOPTION AND ADAPTABILITY OF MODERN AMAN RICE CULTIVARS IN FARIDPUR REGION - BANGLADESH
}

\section{T. CHAKROBARTY*, M. ASADULLA AL GALIB, M. ZAHIDUL ISLAM and M. AKHLASUR RAHMAN}

\author{
Bangladesh Rice Research Institute, Regional Station, Bhanga, Faridpur, Bangladesh \\ *Corresponding author email: tusher.brri@gmail.com \\ Email addresses of co-authors: galib.brri@gmail.com, zahid.grs@gmail.com,akhlas08@gmail.com
}

\section{SUMMARY}

Rice is not just a staple food; but it is at the center of culture, politics, and economy of Bangladesh. The determinants affecting the adoption of modern rice cultivars and their adaptability in the Aman season (June to November) at the Faridpur region in Bangladesh were discussed. A total of 500 farmers from five different districts such as, Faridpur, Madaripur, Shariatpur, Rajbari, and Gopalganj through multistage sampling technique participated in the survey. Before the survey, 15 farmers were selected for the cultivation of eight modern T. Aman rice cultivars in their fields during three consecutive years 2018 to 2020 in the mentioned five districts of Bangladesh. A structured questionnaire was used to identify the determinants associated with the adoption of modern rice cultivars by replacing the popular old ones. Results revealed that beyond preferences, some other determinants (age, education, risk aversion, land size, yield, and perception of modern rice cultivars and their seed availability) directed the decision to adopt or not. Considering the average grain yield of the tested rice cultivars, the genotypes BRRI dhan72 (G-6) and BRRI dhan87 (G-8) were the high yielding cultivars for the above five districts. Despite having a comparatively low yield, the cultivars BRRI dhan71 (G-4) and BRRI dhan49 (G-3) were more stable compared to other cultivars in the Faridpur region of Bangladesh.

Keywords: Adoption, adaptability, heritability, GGE, Aman rice

Key findings: Beyond yield superiority, other important factors, i.e., demographics, risk averted mind of farmers, input availability, varietal characteristics, and cultivars adaptation also determine that whether the cultivar is adopted or not. In the Faridpur region Bangladesh, the rice cultivars BRRI dhan 72 and BRRI dhan87 were preferred due to their yield superiority despite their low adaptability. However, in the context of adaptability and stability, rice genotypes BRRI dhan49 and BRRI dhan71 were found more stable for the Aman season.

Manuscript received: July 26, 2021; Accepted: November 12, 2021.

(C) Society for the Advancement of Breeding Research in Asia and Oceania (SABRAO) 2021

Communicating Editor: Dr. Samrin Gul 


\section{INTRODUCTION}

Rice growing area is about 10.5 million hectares (ha) and 13 million farming families are growing rice in Bangladesh (Hasan, 2015). Bangladesh has produced 38.70 million tons during 2019 (Figure 1) and secured the third position among the rice producing countries (USDA 2021; The Daily Star, Friday, November 5, 2021). The country's rice requirement was about 27.26 million tons during 2020 (Khatun et al., 2020). However, the population is increasing at an alarming position, and net cultivable land for rice crop will be assumed at 7.9 million ha which is not sufficient to meet the ever-increasing demand in Bangladesh (Rahman, 2018; Sayeed and Yunus, 2018). Therefore, the vertical improvement through increased yield and varietal replacement by developing high-yielding modern rice cultivars is the only way to combat the issue.

The Bangladesh Rice Research Institute (BRRI) has developed 106 rice cultivars since its inception in 1970. After its establishment, the rice cultivar BR3 accelerated the rice growth rate of $18.37 \%$ during 1973 to 1974 . By adopting the elite rice cultivar BR11 in the Aman season, rice growth rate reached $13.93 \%$ in 1989 to 90 . The popular two rice cultivars BRRI dhan28 and BRRI dhan29 in the Boro season contributed to the growth rate of $15.89 \%$ during 1990 to 2000 (Figure 2) (BBS, 2020)

To narrow the adoption time of modern rice cultivars, the Department of Agricultural Extension (DAE) played an important role through different demonstrations and farmer's training (Chowdhury et al., 2014). To ensure sustainable food security and double the productivity before 2030 , the development of region-specific modern rice cultivars is running so fast. Therefore, a large number of rice cultivars are available to extension personnel and farmers that make a dilemma for adoption (Singh et al., 2020). Regarding this, instead of a single varietal demonstration, a head-to-head demonstration would be the solution. By using head-to-head demonstration, farmers can get the chance to choose the superior cultivars considering grain yield, growth duration, and grain quality. The head-to-head demonstration concept was originated at BRRI through the transforming rice breeding (TRB) project. Here the first 'head' means popular aged cultivar which is covered a large area in the specific region, e.g., BRRI dhan39 is a popular cultivar in Faridpur region which is relayed with jute and covered a larger area in the Aman season. The last 'head' represents the targeted (new) cultivar which can replace the popular one by farmer's own choice.

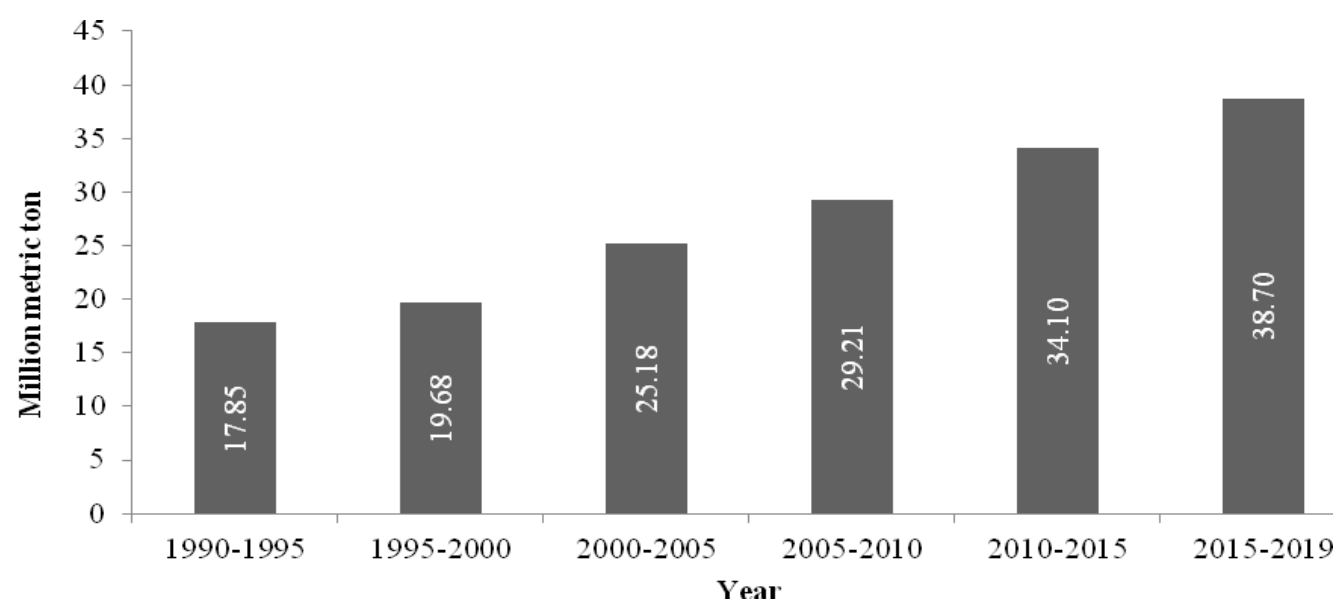

Figure 1. The phenomenon of rice production from 1990-1995 to 2015-2019. 


\section{Year}

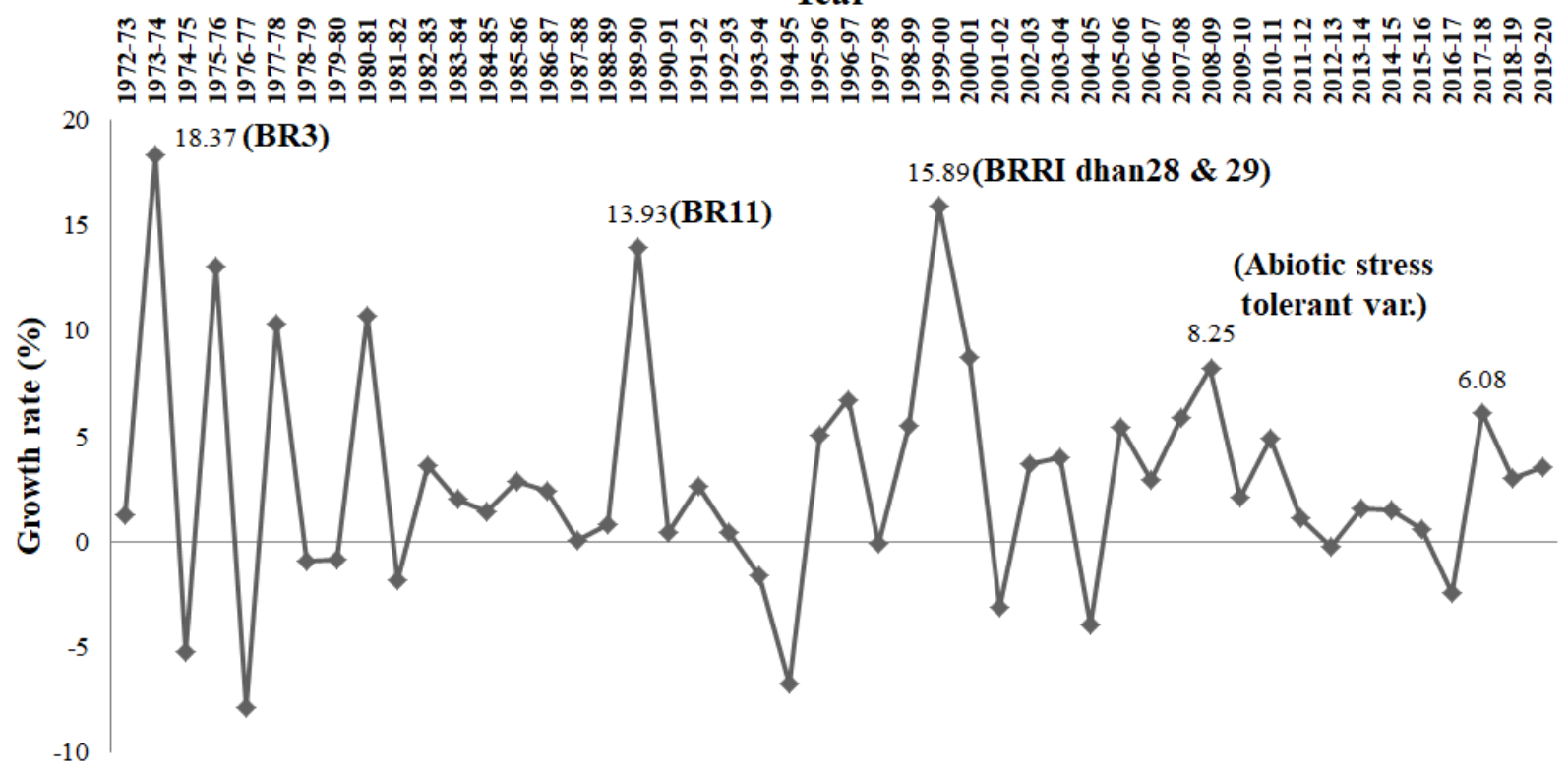

Figure 2. The year-wise growth rate of rice production in Bangladesh shows the growth rate increase in \% with the advent of few milestone rice cultivars (BR3, BR11, BRRI dhan28, BRRI dhan29 and abiotic stress tolerant varieties).

For cultivar development, the greater adaptation of rice cultivar with minimum genotype-environment interaction has attained more importance rather than yield superiority (Tiongco and Hossain, 2015; Walker et al., 2015). By exploring the grain yield stability in different areas, it would be possible to select suitable and well-adaptive cultivars in specific regions which can mitigate the problem. By the supervision of BRRI Regional Station in Bhanga, Faridpur, the studies were conducted during three consecutive years of 2018, 2019, and 2020 each in the five districts, i.e., Faridpur, Madaripur, Shariatpur, Rajbari, and Gopalganj to determine: a) the causes for time to adoption of modern rice cultivars, b) the suitable, stable, and welladapted rice cultivar to replace the popular aged cultivars, and c) the enhancement in rice productivity in Faridpur region of Bangladesh.

\section{MATERIALS AND METHODS}

\section{Study area}

The multi-location study was conducted during three consecutive years of 2018 to 2020 at five different upazilas of five districts namely, Sadar upazila, Faridpur; Rajoir upazila, Madaripur; Zajira upazila, Shariatpur; Sadar upazila, Rajbari; Muksudpur upazila, Gopalganj and were denoted as E1, E2, E3, E4, and E5, respectively. These areas belong to different agro-ecological zones (AEZ), i.e., AEZ - 12 (Lower Ganges River Floodplain), AEZ - 14 (Gopalganj-Khulna Bills), and AEZ - 19 (Old Meghna Estuarine Floodplain) (Brammer, 2017).

\section{Study materials and design}

In Aman 2018, six modern rice cultivars (BRRI dhan49, BRRI dhan71, BRRI 
dhan72, BRRI dhan75, BRRI dhan80, and BRRI dhan87) along with two check cultivars (BRRI dhan39 and BINA dhan-7) were evaluated in a randomized complete block design (RCBD) with three replications (three dispersed locations in one upazila considered as three replications) at five different upazila. After harvesting, around 100 farmers attended participatory cultivar selection (Louwaars) each at five study sites to provide the ranking among these rice cultivars considering grain yield, growth duration, and grain quality. The response of each farmer was recorded and was provided each with $5 \mathrm{~kg}$ seed of ranked one rice cultivar for cultivating in next season. Then the farmers were evaluated whether they cultivated these genotypes or not. During the next season, the evaluated farmers were screened based on the same criteria and identified the prime causes behind the adoption and rejection.

\section{Data collection and analysis}

For all tested cultivars along with checks, the yield $\left(\mathrm{kg} / 10 \mathrm{~m}^{2}\right)$ in three replications at different sites was recorded. Then conversion to $\mathrm{t} \mathrm{ha}^{-1}$ was done using the following formula:

Yield $\left(\frac{t}{h a}\right)=$ Yield $\left(\frac{k g}{10 m 2}\right) *\left(\frac{100-\text { estimated moisture } \%}{100-14}\right)$

Here, rice grain yield is calculated at $14 \%$ moisture.

The frequency of preference and adoption by farmers was counted in PVS and two consecutive seasons. Through scheduled interviews, the factors responsible for adoption beyond preference were identified and stratified based on priority. Descriptive statistics was incurred using STAR V 2.0.1 (IRRI, 2014), and PBTools V 1.4. (IRRI, 2014) were used for GGE (Generalized Gielis equation) analysis to determine the adaptability of those cultivars.

\section{RESULTS AND DISCUSSION}

Secondary data of the Annual Report of DAE, 2017 showed that T. Aman coverage is highly predominant over other minor crops in the existing cropping pattern of Faridpur except for the Shariatpur region. It is continuously increasing due to the inclusion of modern Aman rice cultivars in this region. In 10 major cropping patterns of districts: Faridpur, Madaripur, Rajbari, and Gopalganj; T. Aman hold $1^{\text {st }}, 4^{\text {th }}, 1^{\text {st }}$, and $5^{\text {th }}$ positions, respectively (Figure 3 ). Therefore, by considering T. Aman as a major crop, it would be possible to increase the productivity in the Faridpur region by replacing the existing cultivars through suitable, adaptive, and highyielding rice cultivars.

The analysis of variance for grain yield of the eight cultivars tested in five environments is presented in Table 1. It represents the combined analysis of variance for the grain yield of the eight rice cultivars. Cultivars (G) and cultivar $x$ environment interactions (GEI) were highly significant $(P<0.001)$, while environments (E) were simply significant $(P<0.05)$ for grain yield. The highly significant interactions between cultivars and environments revealed that the cultivars would be selected for adaptation to specific environments, which is aligned with some findings of $G \times E$ interaction effects of hybrid rice genotypes and cassava genotypes, respectively ( $\mathrm{Xu}$ et al., 2014; Akter et al., 2015). Partitioning of explained SS (sum of square) showed that genotypes (cultivars) accounted for $70.71 \%$ variation and contribution of environments and their interactions was $4.23 \%$ and $11.57 \%$ respectively of the total variation (Table 1 ). Hence, $G \times E$ interaction effects demonstrated that genotypes responded differently to the various environmental conditions (soil type, weather, flood inundation, insect and disease prevalence), which brings the 
Faridpur

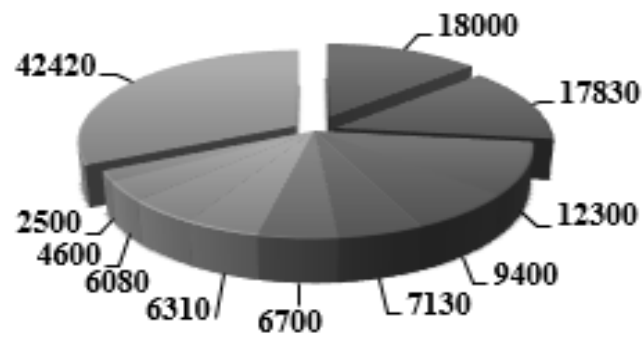

Madaipur
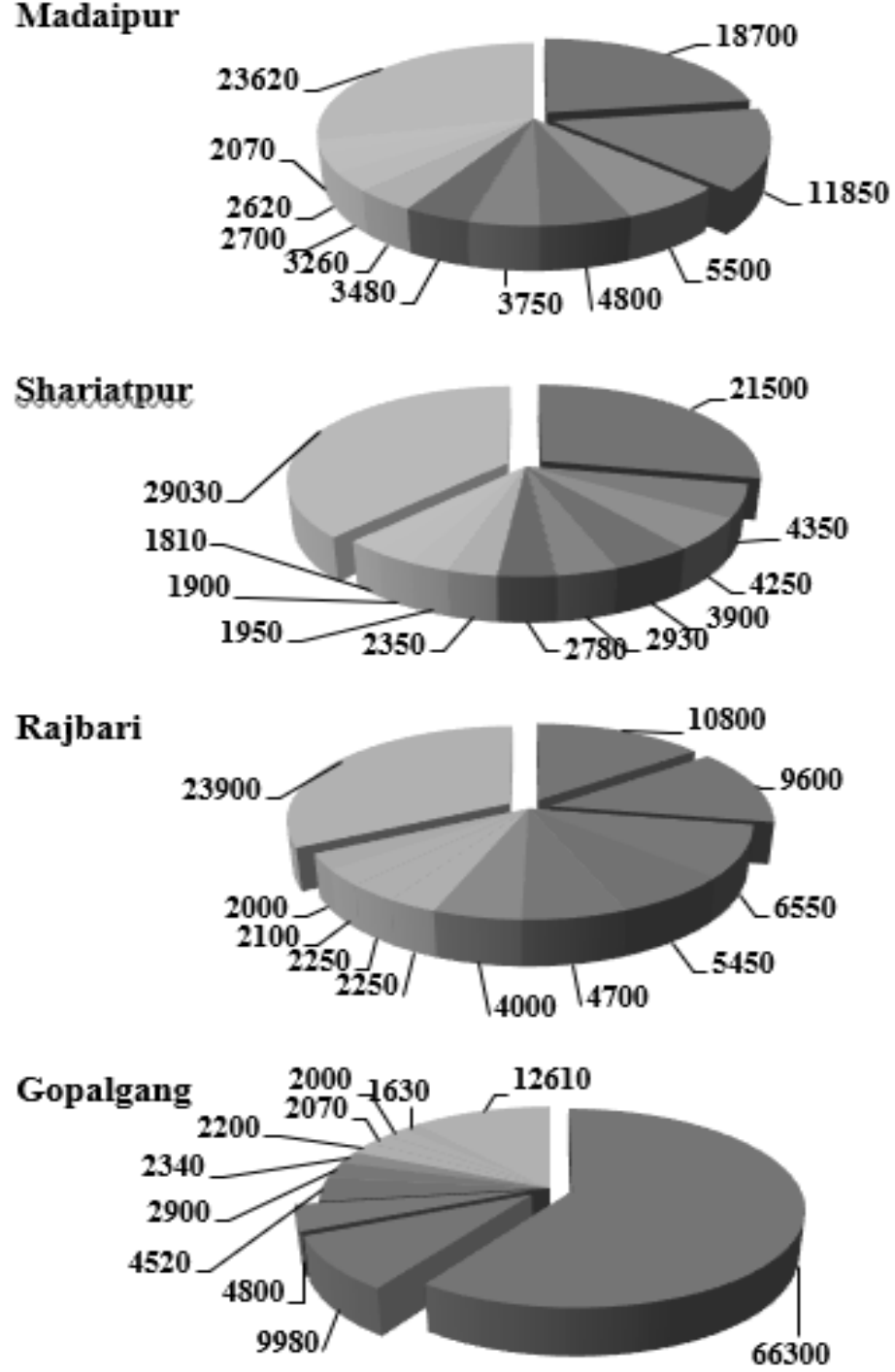

Wheat-Jute-T.Aman Onion-Jute-Fallow Onion-Jute-T.Aman Wheat-Jute-Fallow Boro-B.Aman GBoro-Fallow-Fallow Dentil-Jute-Fallow Boro-Fallow-T.Aman ILentil-Jute-T_Aman Mustard-Jute-T_Ama a Others (consisting of 86 minor CP)

- Boro-Fallow-Fallow
" Boro-B.Aman
" Mustard-Jute-Fallow
" Mustard-Jute-T.Aman
" Lentil-Jute-T.Aman
" Wheat-Jute-Fallow
" Grasspea-Jute-Fallow
- Lentil-Jute-Fallow
- Mustard-Boro-B_Aman
"Garlic-Jute-Fallow
" Others (Consisiting of 47 minor CP)

- Boro-Fallow-Fallow - Mustard-Jute-Fallow

- Chilli-B.Aman - Boro-B.Aman - Grasspea-Jute-Fallow - Coriander-Jute-Fallow Lentil-Jute-Fallow - Vegetab-Jute-Fallow - Mustard-Boro-Fallow

- Wheat-Jute-Fallow

- Others (Consisting of 62 minor CP)

- Wheat-Jute-T.Aman - Onion-Jute-T_Aman

- Boro-Fallow-Fallow -Boro-Fallow-T.Aman Onion-Jute-Fallow Wheat-Jute-Fallow - Lentil-Jute-T_Aman Vegetab-Vegetab-Vegetab Mustard-Boro-Fallow " Lentil-Sesame-T_Aman
- Others (Consisting of 40 minor CP)

Boro-Fallow-Fallow - Boro-B.Aman - Grasspea-Jute-Fallow Wheat-Jute-Fallow - Boro-Fallow-T.Aman - Mustard-Jute-T.Aman = Vegetab-Vegetab-Vegetab Lentil-Jute-Fallow - Lentil-Jute-T.Aman Wheat-Jute-T.Amam - Others (consisting of 47 minor CP)

Figure 3. Status of existing cropping pattern in Faridpur region, Bangladesh, comprised of five districts. (Clockwise fragmentation represents the cropping pattern list respectively). 
Table 1. Combined analysis of variance of grain yield for eight rice cultivars evaluated at five environments.

\begin{tabular}{llllll}
\hline Source of variation & d.f. & S.S. & Explained SS (\%) & M.S.S. & $\operatorname{Pr}(>\mathrm{F})$ \\
\hline Environment (E) & 4 & 1.5462 & 4.25 & $0.3866^{*}$ & 0.0425 \\
Block within Environment & 10 & 1.045 & 2.87 & $0.1045^{*}$ & 0.05 \\
Cultivar (G) & 7 & 25.7255 & 70.7 & $3.6751^{* * *}$ & 0.0002 \\
Environment x Cultivar (GEI) & 28 & 4.2098 & 11.57 & $0.1504^{* * *}$ & 0.0004 \\
Pooled Error & 70 & 3.8534 & 10.58 & 0.055 & - \\
Total & 119 & 36.38 & & - & - \\
\hline
\end{tabular}

Table 2. Varietal performance and heritability across different environments in Faridpur region, Bangladesh.

\begin{tabular}{llllll}
\hline Cultivars & Environ. 1 & Environ. 2 & Environ. 3 & Environ. 4 & Environ. 5 \\
\hline BINA Dhan7 (Check) & $4.72 \mathrm{bc}$ & $4.77 \mathrm{bc}$ & $4.83 \mathrm{bc}$ & $4.73 \mathrm{c}$ & $5.21 \mathrm{~b}$ \\
BRRI dhan39 (Check) & $4.58 \mathrm{bc}$ & $4.4 \mathrm{c}$ & $4.56 \mathrm{c}$ & $4.57 \mathrm{c}$ & $4.42 \mathrm{~cd}$ \\
BRRI dhan49 & $4.41 \mathrm{c}$ & $4.77 \mathrm{bc}$ & $4.78 \mathrm{bc}$ & $4.89 \mathrm{bc}$ & $4.42 \mathrm{~cd}$ \\
BRRI dhan71 & $4.73 \mathrm{bc}$ & $5.09 \mathrm{ab}$ & $5.23 \mathrm{~b}$ & $5.63 \mathrm{a}$ & $5.17 \mathrm{~b}$ \\
BRRI dhan72 & $5.07 \mathrm{~b}$ & $4.85 \mathrm{bc}$ & $5.35 \mathrm{~b}$ & $5.41 \mathrm{ab}$ & $4.93 \mathrm{bc}$ \\
BRRI dhan75 & $5.03 \mathrm{~b}$ & $4.80 \mathrm{bc}$ & $5.07 \mathrm{bc}$ & $4.89 \mathrm{bc}$ & $4.74 \mathrm{~b}-\mathrm{d}$ \\
BRRI dhan80 & $4.38 \mathrm{c}$ & $4.26 \mathrm{c}$ & $4.78 \mathrm{bc}$ & $4.47 \mathrm{c}$ & $4.17 \mathrm{~d}$ \\
BRRI dhan87 & $6.40 \mathrm{a}$ & $5.50 \mathrm{a}$ & $6.31 \mathrm{a}$ & $5.79 \mathrm{a}$ & $5.88 \mathrm{a}$ \\
\hline Heritability & 0.98 & 0.86 & 0.93 & 0.92 & 0.93 \\
LSD 0.05 & 0.5986 & & & & \\
CV $(\%)$ & 4.74 & & & & \\
\hline
\end{tabular}

E1 = Sadar upazila, Faridpur; E2 = Rajoir upazila, Madaripur; E3 = Zajira upazila, Shariatpur; E4 = Sadar upazila, Rajbari, E5 = Muksudpur upazila, Gopalganj

need of testing rice cultivars at multiple locations. Louwaars (2018) stated that plant breeders also face lots of problems and must work very hard in selecting new cultivars for specific regions and agroecological zones due to ever existing environmental and genotype effects.

In the context of yield performance, cultivar BRRI dhan 87 was the superior among all tested environments. In contrast, BRRI dhan 80 was identified as the poorest cultivar in E1, E2, E4, and E5. However, in E3, genotype BRRI dhan39 produced significantly lowest grain yield. Rice cultivars with similar means showed nonsignificant differences among them. Plant breeders use heritability to estimate the precision in single field trials and the series of field trials (Piepho and Mo" hring, 2007; Oladosu et al., 2014). Here in E1, the heritability was the highest $(0.98)$ which indicated that $98 \%$ proportion of phenotypic variance (yield performance) among the population was due to heritable genetic effects (Table 2).

The box plots explained overall patterns of varietal yielding response in a group from under different environments (Figure 4). The range and other characteristics of responses were visualized for a larger group here. In E5, the median was close to the mean revealing that there was an existing lot of variation in the performance of tested cultivars. In $\mathrm{E} 4$, the $50 \%$ population yielded 4.50 to 5.52 tons $\mathrm{ha}^{-1}$ which accounted in the middle box, and the maximum population was accounted for the higher grain yield. In E1, two outliers were present and accounted for $1.6 \%$ of the total population but the inter-quartile box was comparatively short to others which represents that the performance of the tested populations were close to each other (Bruno et al., 2017). 


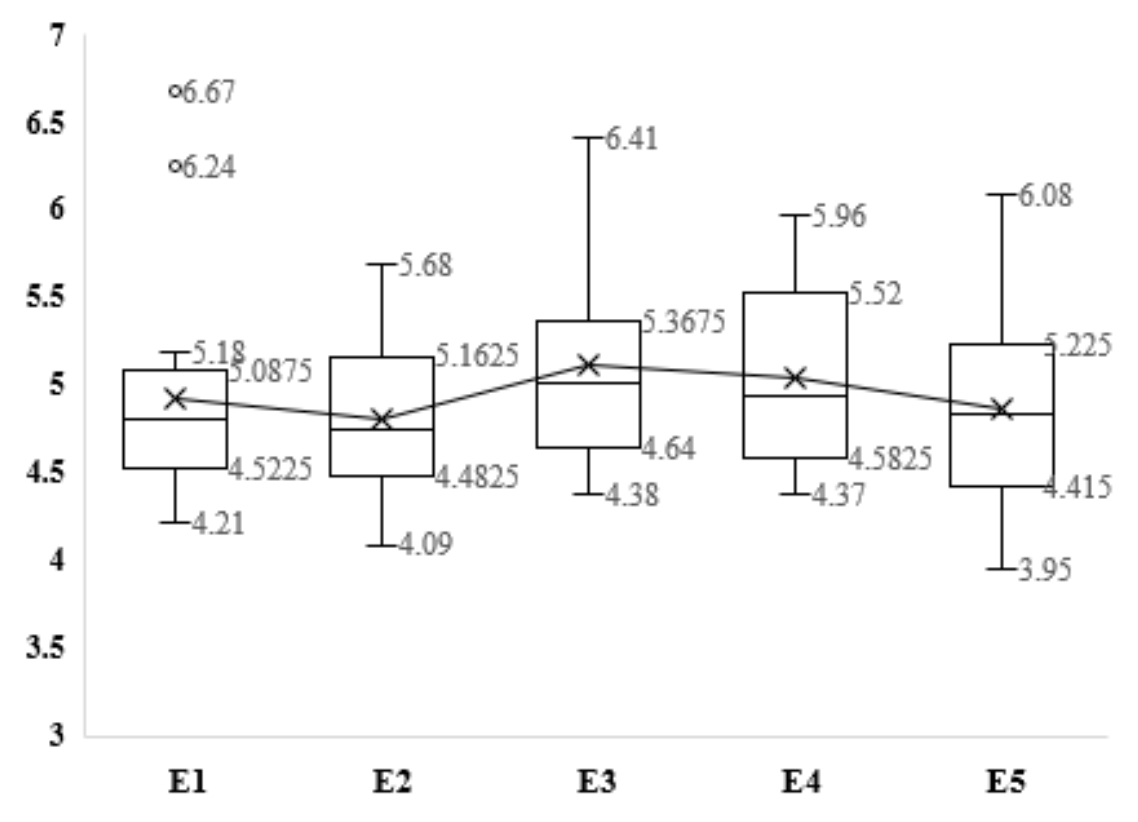

Figure 4. Boxplot of tested varietal yield performance in environments.

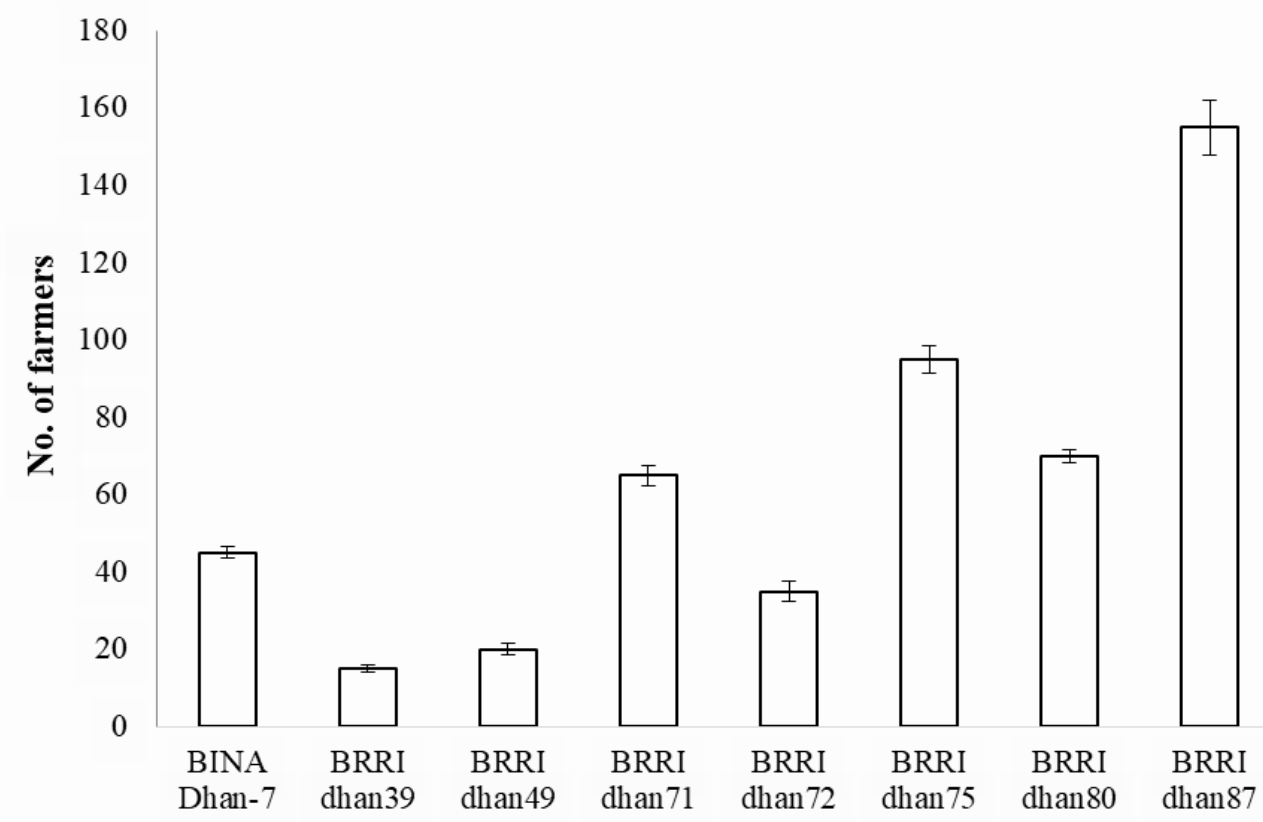

Figure 5. Farmer's preferences in the tested cultivars.

By summarizing the 500 farmers in the five specific upazilas, the genotype BRRI dhan87 was preferred by 155 farmers due to higher grain yield (Figure 5). The second preference was the cultivar BRRI dhan75 for short duration by 95 farmers. This cultivar got popularity in other regions, i.e., Rangpur and Dinajpur for its compatibility in three crop-based systems along with potentiality to escape moisture (Kabir et al., 2019). The third highest choice was the rice genotype BRRI 
dhan-80 for long slender premium quality grain. The rainfall pattern was sporadic due to climate change, and the droughttolerant cultivar BRRI dhan71 in rainfed Aman season got the preference of 65 farmers as it is highly accepted in Rangpur and Dinajpur regions where drought is common in Aman season (Kabir et al., 2019). For $\mathrm{Zn}$ enrichment in cultivar BRRI dhan72, 35 farmers showed their willingness to cultivate in the next season and further. Rice is the important staple food that contributes $70 \%$ per capita of caloric intakes in Bangladesh (FAO, 2009). So, to ensure dietary Zn sufficiency, modifications to the zinc content of rice would be possible through bio-fortification (Dipti et al., 2017). The grain size of the cultivar BRRI dhan49 is close to a local cultivar 'Nizersail', considering this character and the 20 farmers showed their interest in it. A total of 45 and 15 farmers were found happy with their existing rice cultivar BINA Dhan7 and BRRI dhan39, respectively in the Aman season.

In 2018, the seed of the preferred rice cultivar was provided to farmers for cultivation in the next season. During 2019, the highest farmers' preference $(78.6 \%)$ was achieved in the genotype BRRI dhan80 due to its fine grain (Figure 6). High yielding cultivars BRRI dhan 87 and BRRI dhan75 obtained $77.4 \%$ and $74.7 \%$, respectively because of their short duration in maturity. However, the lowest $(42.9 \%)$ was observed in BRRI dhan72 despite its Zn content (Figure 6). In 2020, a heavy flood happened in Bangladesh, and consequently, the Faridpur region was tremendously affected as it lay in flood affected areas. Almost the entire Aman rice crop was affected due to the inundation of the seedbed and main field. Recovery was done by getting the seed support of photosensitive cultivars (BR22, BR23, and local cultivar Nizersail) which were popular cultivars in flood prone areas (Hossain, 2015). For that reason, in 2020, the cultivation percentage was drastically reduced at the experimental sites. However, due to cultivation in medium high lands and existing embankment, the high yielding cultivar BRRI dhan87 cultivation percentage was close to the previous year. After all those observations, a scheduled interview was conducted to identify the determinants associated with the adoption of modern rice cultivars. Ghimire et al. (2015) mentioned agro-ecological regions, extension services, and seeds all played important roles in adoption decisions.

Adoption of different rice cultivars depends on the independent variables, which are considered as demographic, management, production, and postharvest characteristics. This is agreed with the utility maximization theory by Rahm and Huffman (1984). The adoption is far beyond the decision of farmers to adopt or not. Along with a lot of factors that is still anchored with it (Asaduzzaman, 1979; Hossain et al., 2006; Ahmed et al., 2016; Bannor et al., 2020). Under these determinants, several sub-factors have been identified that influence the adoption of modern rice cultivars in the Faridpur region (Figure 7 ).

Polygon view through GGE analysis displayed the winning genotypes with their interaction behavior across the tested environments (Figure 8). A polygon was developed by joining the vertex cultivars (G4, G3, G7, and G8) with a solid straight line, and other cultivars (G1, G2, G5, and G6) remain within this polygon. The distance of the vertex cultivars was higher than other genotypes. It means that the vertex cultivars were more responsive to their environments than other cultivars and were considered as specially adapted cultivars (Yan and Rajcan, 2002; Ogunbayo et al., 2014). In some environments, it performs well or poor along with farmer's preferences for their special traits (aroma, and slender grain). Genotypes G1, G5, and G6 were located closer to the origin of Biplot, were less responsive and more adaptive than other tested cultivars (Yan et al., 2007).

Biplot was divided into three sections by three perpendicular lines starting from the origin and extended over the polygon. The tested cultivars were partitioned and placed in these three sections. The $1^{\text {st }}$ section contains two 


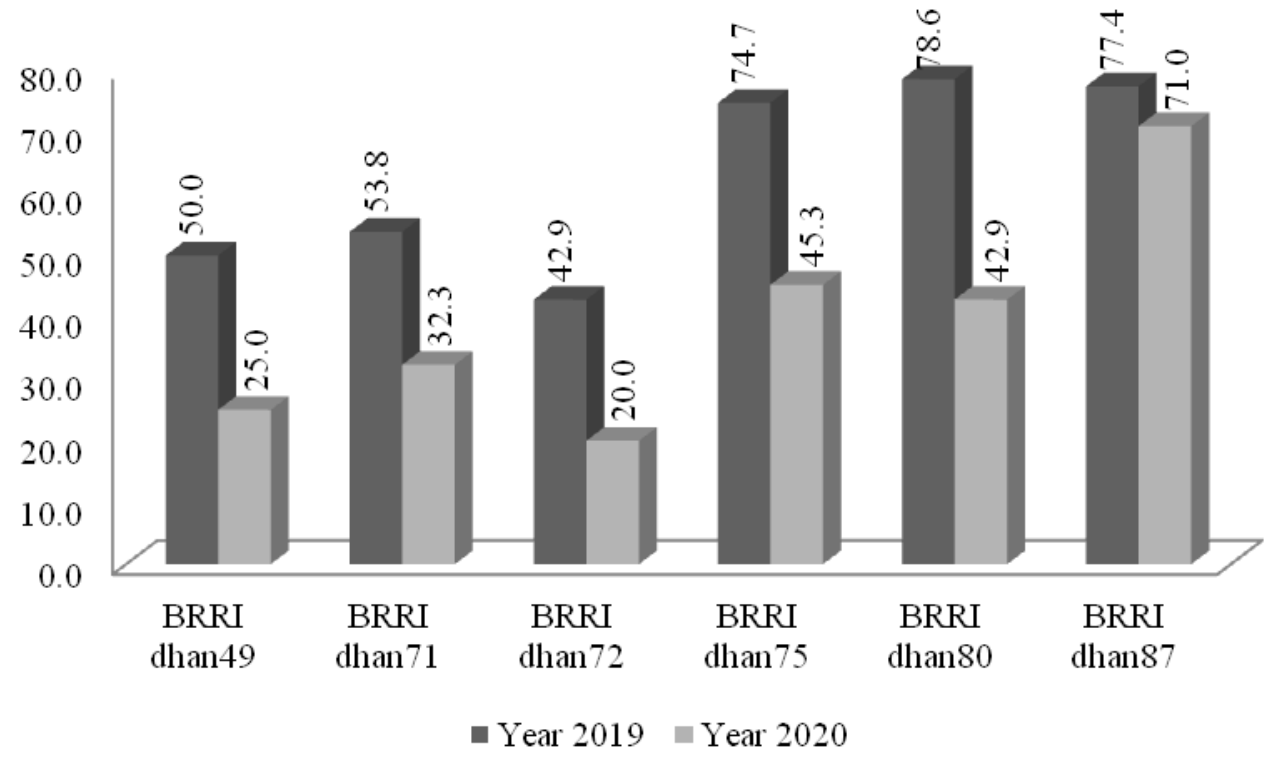

Figure 6. Percentage (\%) of preferred cultivar cultivation in two consecutive years at the selected sites.

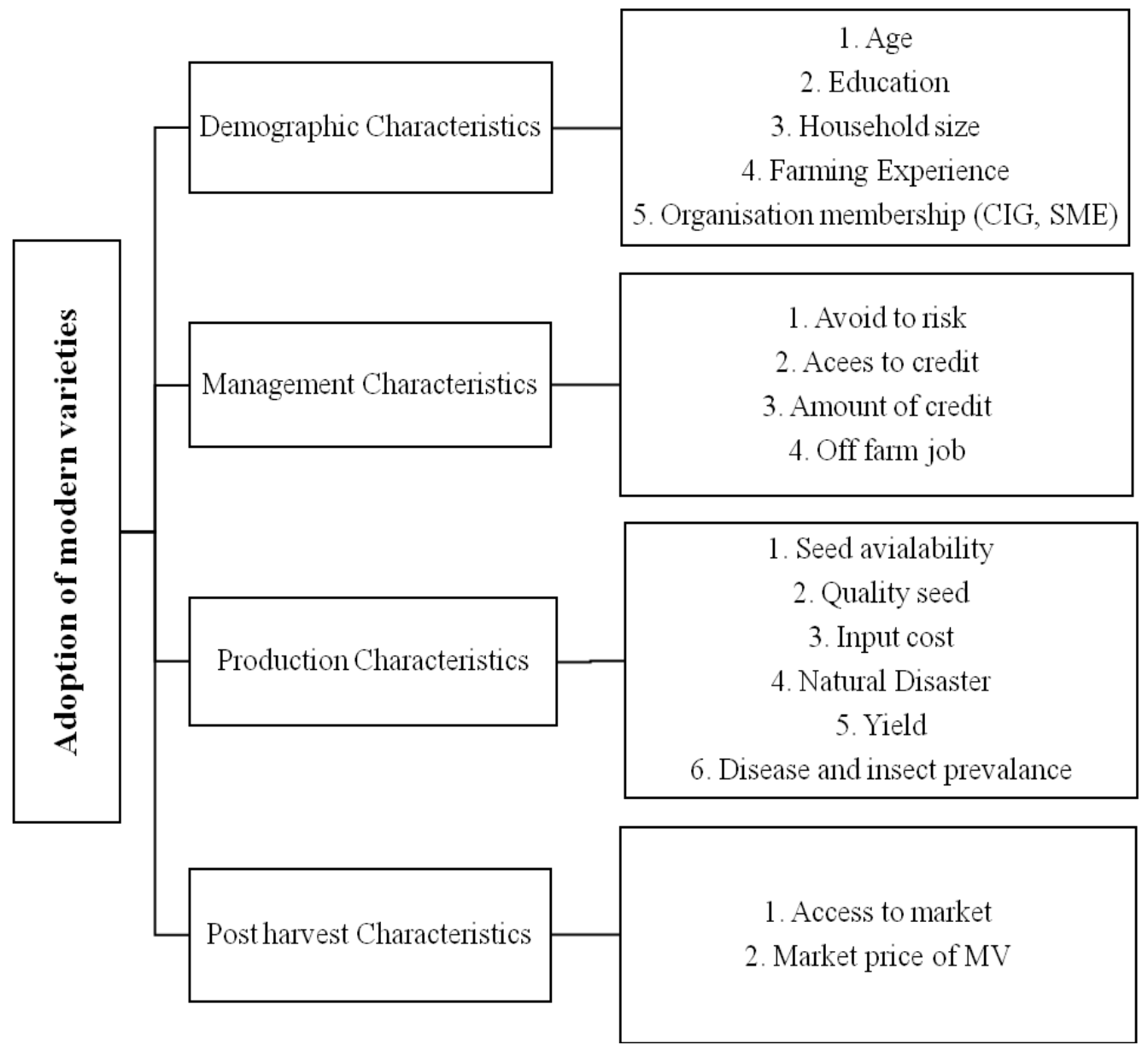

Figure 7. Determinants of adoption of modern cultivars. 


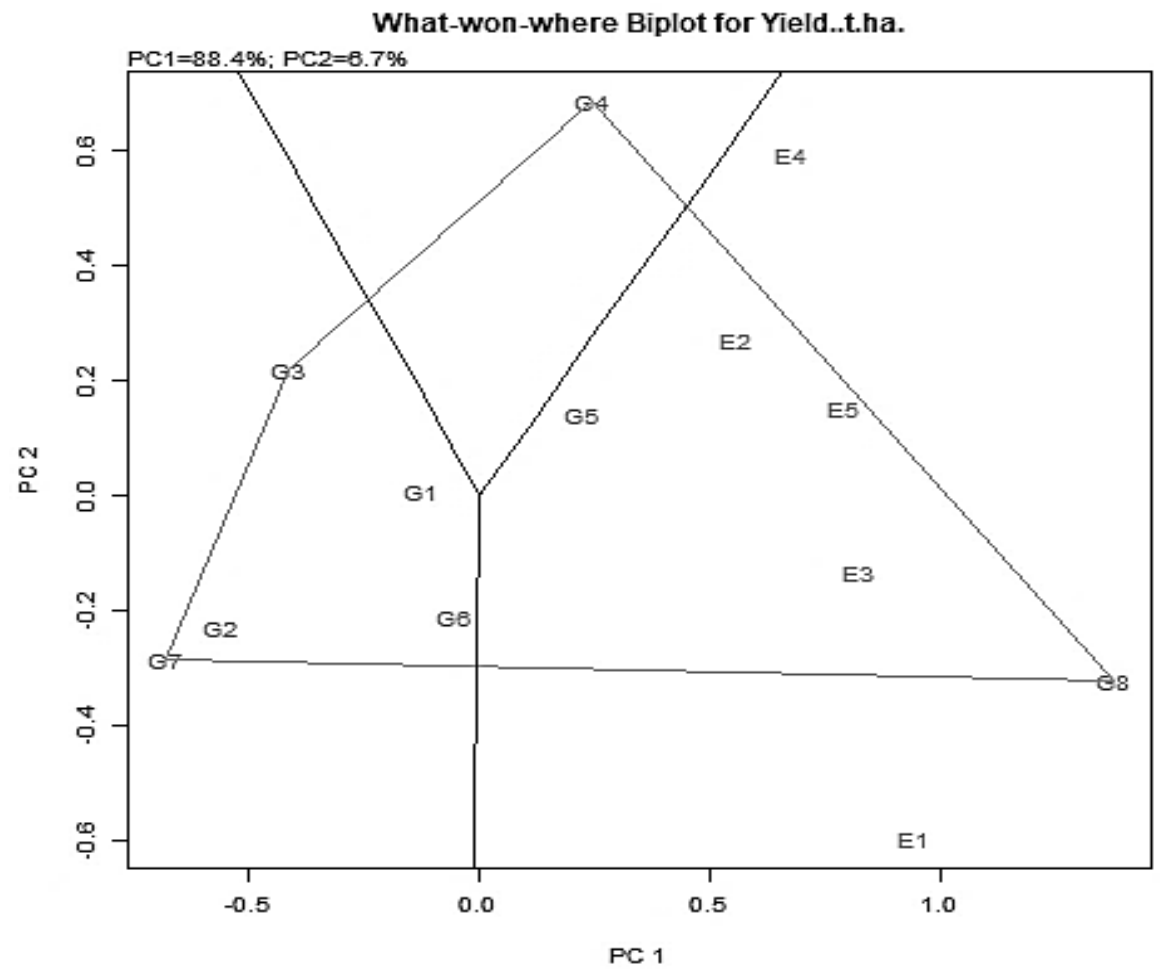

Figure 8. Polygon view of GGE biplot analysis.

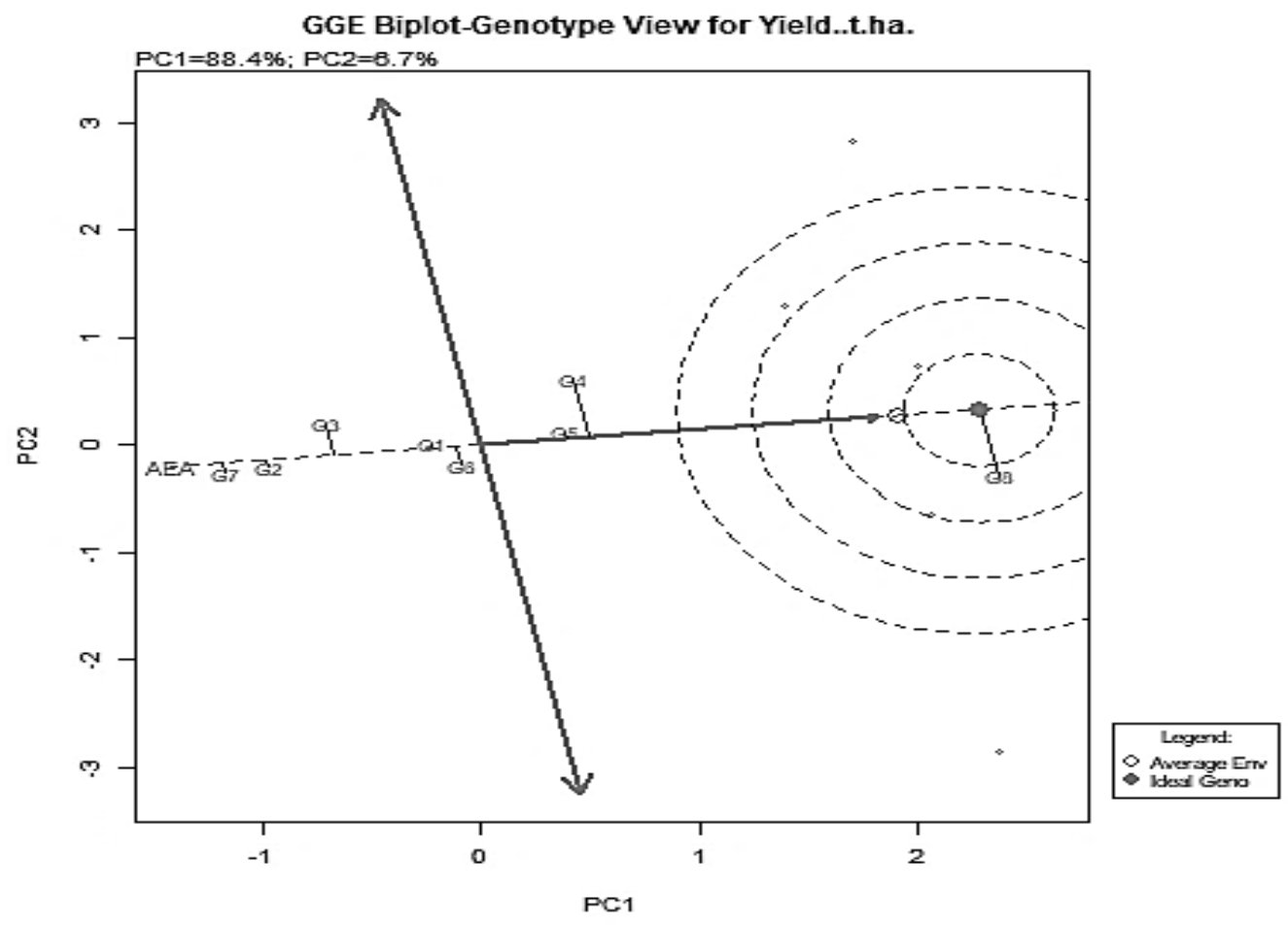

Figure 9. Ranking of genotypes based on mean yield and stability performance. 


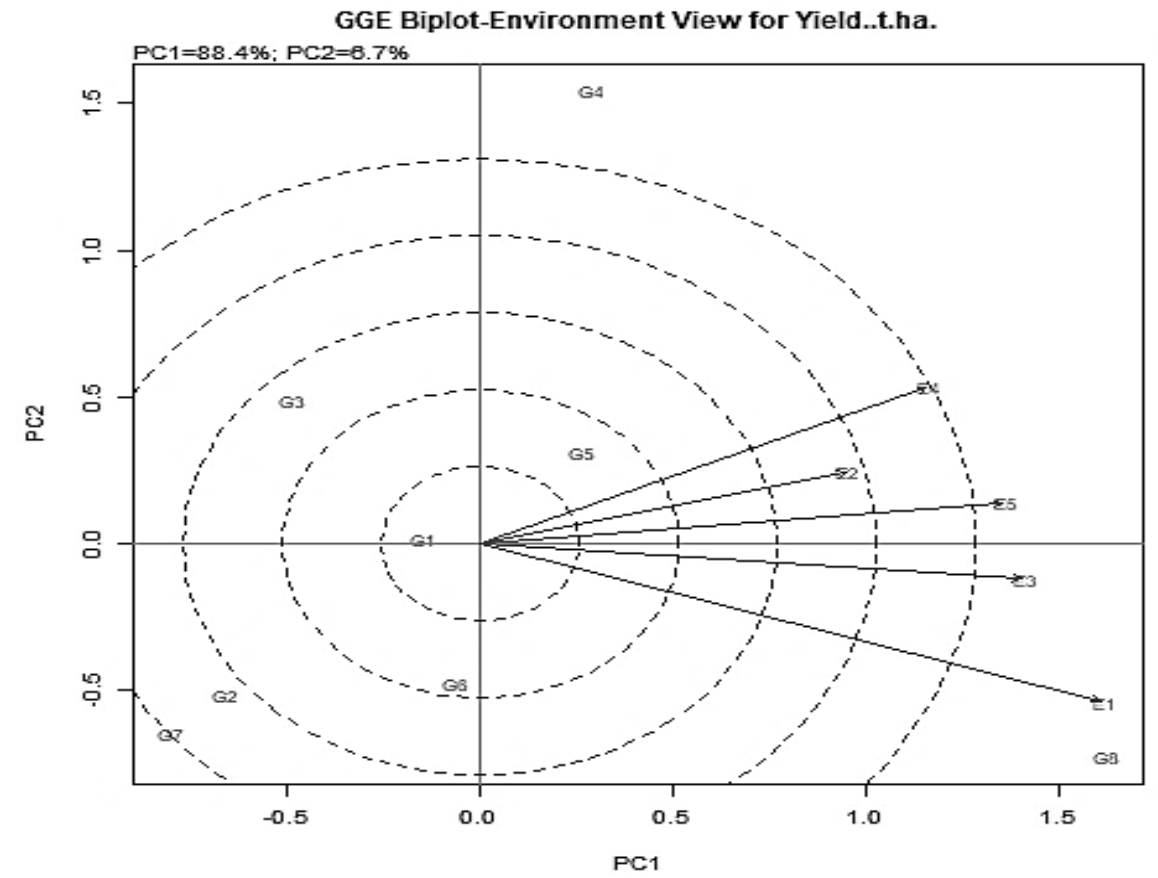

Figure 10. Relationship among environments.

cultivars named by BRRI dhan72 (G6) and BRRI dhan87 (G8) (Vertex cultivars) which were identified as the high yielding genotypes for these five locations. Only one cultivar BRRI dhan71 (G4) was felt in $2^{\text {nd }}$ section and the rest of these were in $3^{\text {rd }}$ section. In the present investigations, GGE biplot analysis estimated $88.4 \%$ and $6.7 \%$ variations for PC1 and PC2 GGE sum of squares, respectively which explained $95.1 \%$ of the total variance.

The average grain yield performance and stability of tested rice cultivars were indicated in Figure 9. Average Environmental Axis (AEA) passes across the biplot origin. In the $A E A$, the central pointed blue circle corresponds to the average environment while the ideal cultivar was represented by a blue solid dot. High yielding rice cultivars were close to the blue circle in the AEA. The cultivars in the upper position on the AEA were identified as more stable and those that were below on the AEA were considered as less stable to the environments (Akter et al., 2015; Donoso-Nanculao et al., 2016; Pagi et al., 2017). That cultivar had large PC1 scores and was considered as high mean yield and small PC2 scores for high stability. Although such an 'ideal' cultivar may not be found in reality, but it could provide a reference for genotype evaluation (Mitrovic et al., 2012). By considering these factors, BRRI dhan87 (G8) was found as the high yielding rice cultivar. In the context of stability, rice cultivars BRRI dhan71 (G4) and BRRI dhan49 (G3) were found to be more stable than others. Results further revealed that the area of cultivars on the right side of the perpendicular line has shown the best performance and greater yield than mean yield and the genotypes on the left side which were observed with less grain yield compared to average yield. In the present study, the rice cultivars BRRI dhan87 (G8), BRRI dhan71 (G4), and BRRI dhan72 (G5) were high yielding than all others. Stability parameters and breeding values based on pedigree information of different elite breeding lines for yield under salt stress were estimated in Bangladesh (Quddus et al., 2019). 
The GGE biplot model is an efficient method to visualize MET data analysis (Mohammadi et al., 2011; Quddus et al., 2019). GGE illustrated that a total variation of $95.1 \%$ was accounted which consisting of $88.4 \%$ and $6.7 \%$ attributed to the $\mathrm{PC} 1$ and $\mathrm{PC2}$, respectively (Figure 10). The E2 and E4 environments were ideal for cultivar G5 (BRRI dhan-72). The E5 and E3 were considered as the least environments for all the cultivars. However, the E1 environment was the most suitable environment for cultivar G8 (BRRI dhan87). In the biplot environment view, the relationship among the environments was explicated by the relationship between the environments that were measured by their vector size and angle between the two environments (Yan et al., 2001). The E1 and E3 had the longer vectors thus, they were the ideal environments for genetic discrimination of the cultivars but on considering the angle between these two environments, these environments were comparatively less discriminating than E5, E2, and E4. The environment E2 was the least representative environment in the present study because it has a shorter vector. The minimum angle between the vectors of E2 and $\mathrm{E} 5$ has shown a robust correlation that is in agreement with the past studies on hybrid rice in Bangladesh (Akter et al., 2015).

\section{CONCLUSIONS}

To mitigate the emerged problem of achieving sustainability in rice production, varietal replacement should be ensured. In Bangladesh, few rice cultivars are cultivated in the major rice growing areas for almost 22 years. Thus, the replacement of those cultivars should not be overlooked to ensure food security in the diversified agro-ecology along with the risk-averted farming community. It also confirms that these farmers prefer to keep pace with rice cultivars with assured yields rather than do experiment with new ones. For that reason, several complementary varietal performances were demonstrated to increase the interest in new technologies and find a suitable, profit redeemed, and adaptable rice cultivar for the farming community. Therefore, it is a highly commendable job if it monitors the adoption, adaptability, and stability status of new rice cultivars promoted to the field level. In the Faridpur region, the cultivars BRRI dhan72 and BRRI dhan87 were identified as high yielding genotypes, followed by BRRI dhan49 and BRRI dhan71 as stable cultivars for the Aman season.

\section{REFERENCES}

Ahmed AU, Hernandez R, Naher F (2016). Adoption of stress-tolerant rice varieties in Bangladesh. In: $F$. Gatzweiler, J. von Braun, eds., Technological and Institutional Innovations for Marginalized Smallholders in Agricultural Development. Springer, Cham.

Akter A, Hasan MJ, Kulsum $U$, Rahman $M H_{\text {, }}$ Khatun M, Islam MR (2015). GGE biplot analysis for yield stability in multienvironment trials of promising hybrid rice (Oryza sativa L.). Bangladesh Rice J. $19(1): 1-8$.

Asaduzzaman M (1979). Adoption of HYV rice in Bangladesh. Bangladesh Dev. Stud. 7(3): 23-52.

Bannor RK, Kumar GAK, Oppong-Kyeremeh H, Wongnaa CA (2020). Adoption and impact of modern rice varieties on poverty in Eastern India. Rice Sci. 27(1): 56-66.

BBS (Bangladesh Bureau of Statistics) (2020). Statistical Year Book of Bangladesh, Statistics Division, Ministry of Planning, The Government of Peoples Republic of Bangladesh.

Brammer H (2017). Bangladesh's diverse and complex physical geography: implications for agricultural development. Int. J. Environ. Stud. 74(1): 1-27.

Bruno A, Clare MM, Stanley NT, Paul G, Maxwell MG, Patrick R, Richard E (2017). Variety $\times$ environment $\times$ management interaction of diseases and yield in selected common bean varieties. Agron. J. 109(6): 2450-2462.

Chowdhury AH, Hambly Odame $\mathrm{H}$, Leeuwis $\mathrm{C}$ (2014). Transforming the roles of a 
public extension agency to strengthen innovation: Lessons from the National Agricultural Extension Project in Bangladesh. J. Agric. Edu. Ext. 20(1): 7-25.

DAE (Department of Agricultural Extension) (2017). Annual Report, Ministry of Agriculture, The Government of peoples Republic of Bangladesh.

Dipti SS, Hotz C, Kabir KA, Bipul M (2017). Changes in the zinc content of selected Bangladeshi rice varieties through modified parboiling and milling methods. SAARC J. Agric. 15(2): 3143.

Donoso-Nanculao G, Paredes M, Becerra V, Arrepol C, Balzarini M (2016). GGE biplot analysis of multi-environment yield trials of rice produced in a temperate climate.ChileanJ. Agric. Res. 76(2): 152-157.

FAO (2009). Food Balance Sheets (Bangladesh). Accessed online, September 23, 2013Ghimire R, WenChi H, Shrestha RB (2015). Factors affecting adoption of improved rice varieties among rural farm households in Central Nepal. Rice Sci. 22(1): 3543.

IRRI (2014). Plant Breeding Tools (PB Tools), Version: 1.4, International Rice Research Institute, Los Banos, Philippines.

IRRI (2014). Statistical Tool for Agricultural Research (STAR), Version: 2.0.1, International Rice Research Institute, Los Banos, Philippines.

Louwaars NP (2018). Plant breeding and diversity: A troubled relationship? Euphytica 214(114): 1-9.

Hasan M (2015). Adoption of modern practices in rice cultivation by the farmers of Madhukhali upazila under Faridpur District. Ph.D. Dissertation, Department of Agricultural Extension and Information System, Sher-eBangla Agricultural University, Bangladesh.

Hossain MI, Rahman NMF, Kabir MS, Siddique MAB, Tareq M (2015). Development and validation of producer and consumer preference models for rice varieties in Bangladesh. Bangladesh Rice J. 19(1): 63-71.

Hossain M, Bose ML, Mustafi BA (2006). Adoption and productivity impact of modern rice varieties in Bangladesh. Dev. Econ. 44(2): 149-166.
Kabir MJ, Islam MA, Rahman MC, Rahaman MS, Kabir MS, Siddique MAB (2019). Diffusion of wet season ( $T$. aman) rice cultivars under changed environment in Northwest Bangladesh. Bangladesh Rice J. 23(1): 81-106.

Khatun S, Mondal MMA, Khalil MI, Roknuzzaman M, Mollah MMI (2020). Growth and yield performance of six aman rice varieties of Bangladesh. Asian Res. J. Agric. 12(2): 1-7.

Mitrovic B, Stanisavljevi D, Treski S, Stojakovic M, Ivanovic M, Bekabac G, Rajkovic M (2012). Evaluation of experimental maize hybrids tested in multi-location trials using AMMI and GGE biplot analysis. Turkish J. Field Crops 17(1): 35-40.

Mohammadi $R$, Armion $M$, Sadeghzadeh $D$, Amri A, Nachit M (2011). Analysis of genotype- by-environment interaction for agronomic traits of durum wheat in Iran. Plant Prod. Sci. 14: 15-21.

Ogunbayo SA, Sie M, Ojo DK, Popoola AR, Oduwaye OA, Daniel IO, Mercado EF (2014). Comparative performance of forty-eight rice genotypes in diverse environments using the AMMI and GGE biplot analyses. Int. J. Plant Breed. Genet. 8(3): 139-152.

Oladosu Y, Rafii MY, Abdullah N, Abdul Malek M, Rahim HA, Hussin G, Kareem I (2014). Genetic variability and selection criteria in rice mutant lines as revealed by quantitative traits. The Scien. World J. 2014. 190531 |https://doi.org/10.1155/2014/190531

Pagi N, Prajapati N, Pachchigar K, Dharajiya D, Solanki SD, Soni N, Patel P (2017). GGE biplot analysis for yield performance of grain amaranth genotypes across different environments in Western India. J. Exp. Biol. Agric. Sci. 5(3): 368-376.

Piepho HP, Mo"hring J (2007). Computing heritability and selection response from unbalanced plant breeding trials. Genet. 177(3): 1881-1888.

Quddus MR , Rahman MA, Jahan N, Debsharma SK, Disha RF, Hasan MM, Aditya TL, Iftekharuddaula KM, Collard BCY (2019). Estimating pedigree-based breeding values and stability parameters of elite rice breeding lines for yield under salt stress during the boro season, Bangladesh. Plant Breed. Biotechnol. 7(3):257-271 
Rahman M (2018). Agricultural productivity and domestic food availability in Bangladesh. Ph.D. Dissertation, Murdoch University, Australia.

Rahm MR, Huffman WE (1984). The adoption of reduced tillage: the role of human capital and other variables. Am. J. Agric. Econ. 66(4): 405-413.

Sayeed KA, Yunus MM (2018). Rice prices and growth, and poverty reduction in Bangladesh. FAO, Rome, Italy.

Singh RP, Chintagunta AD, Agarwal DK, Kureel RS, Kumar SJ (2020). Varietal replacement rate: Prospects and challenges for global food security. Glob. Food Sec. 25: 100324.

The Daily Star (National Daily Newspaper), The rice economy, Accessed online, November 5, 2021. https://www. thedailystar.net/business/economy/ne ws/the-rice-economy-2114957

Tiongco M, Hossain M (2015). Adoption of modern varieties and rice varietal diversity on household farms in Bangladesh. HarvestPlus Working Paper 22: 3-4.

USDA (2021). Grain and feed update (Bangladesh), Accessed online, July 22,
2021. https://www.fas.usda.gov/data / bangladesh-grain-and-feed-update- 20 .

Walker TS, Alwang J, Alene A, Ndjuenga J, Labarta $R$, Yigezu $Y$, Charyulu DK (2015). Varietal adoption, outcomes and impact. In: TS Walker, J Alwang, eds., Varietal Adoption, Outcomes and Impact. Crop Improvement, Adoption and Impact of Improved Varieties in Food Crops in Sub-Saharan Africa, 506 Windsor Forest Court, Fletcher, North Carolina, USA.

Yan W, Kang MS, Ma B, Woods S, Cornelius PL (2007). GGE biplot vs. AMMI analysis of genotype - by - environment data. Crop Sci. 47(2): 643-653.

Yan W, Rajcan I (2002). Biplot analysis of test sites and trait relations of soybean in Ontario. Crop Sci. 42(1): 11-20.

Yan W, Cornelius PL, Crossa, J, Hunt LA (2001). Two types of GGE biplots for analyzing multi-environment trial data. Crop Sci. 41(3): 656-663.

Xu FF, Tang FF, Shao YF, Chen YL, Chuan T, Bao JS (2014). Genotype $X$ environment interactions for agronomic traits of rice revealed by association mapping. Rice Sci. 21(3): 133-141. 